\title{
The Effect of Nunan's Six Elements of Task to Improve Students Competencies in Legal English
}

\author{
Wang Min \\ School of Foreign Languages, China University of Political Science and Law, China
}

Copyright (C) 2016 by authors, all rights reserved. Authors agree that this article remains permanently open access under the terms of the Creative Commons Attribution License 4.0 International License

\begin{abstract}
This paper is to study the effect of the six elements of task put forward by Nunan on the improvement of students' competencies in legal English, hoping to provide an important glimpse of how current legal English teaching in Chinese universities meets the requirements of the curriculum and the needs of the learners. Based on a case study of college students in China University of Political Science and Law, classes incorporating the six elements to teach both content and language are valid to offer students more exposure to practical extra-linguistic skill building instead of mechanical drills of the linguistic features and translation of legal English.
\end{abstract}

Keywords Legal English, Nunan's Elements of Task, Students Competencies

\section{Introduction}

The recent decade has witnessed an ever-increasing demand for law professionals proficient in English. According to the data provided at www.Chinalawjob.com, in China, $85 \%$ of the positions require law professionals to be competent in legal English, but only 18\% of Chinese laws practitioners meet this requirement. Therefore, nearly $64 \%$ of the cases involving foreign affairs have to be put aside because of the shortage of professionals with sufficient mastery of both law and legal English [1]. It is true that the global communication in this field will help to tackle the problem, however, there is a real possibility that these law talents come from universities who offer key courses of legal English.

\section{Existing Problems in Legal English Teaching}

As a key course of training skilled legal talents, Legal English in China has been given greater interest and awareness. It is one branch of ESP (English for Specific Purpose) and is born in response to certain needs, i.e. the needs of dealing with international legal affairs and enhancing global communication. Legal English classes are designed to cultivate students' ability to read and use legal documents and handles cases involving foreign affairs by incorporating expertise in both language and law. But the effectiveness of legal English courses has been greatly undermined due to the ineffectiveness of the teaching mode.

The separation of the instruction of legal contents and language skills is a major contributing factor to the failure of current legal English classes. The focus of the instruction of legal English of a large number of teachers is to introduce the basic knowledge of law of Common Law System countries, familiarize the students with technical terms and improve their translation skills. Specifically speaking, due to in-class time limit, it is a common practice that teachers cram comprehensive knowledge of law into a few English classes so as to broaden the students' horizon on the concepts and theories of law through authentic English materials. By doing so, legal English courses are similar to traditional teacher-led extensive reading classes with teachers explaining and students memorizing. Most of the time in class is given to the instruction of the linguistic features of legal English [2] and the mechanical drills of the translation of the legal texts. This teaching mode not only separates the student from real world communication, but also indicates the different views on the objectives of legal English teaching.

\section{Controversies over the Objectives of Legal English Teaching}

Teaching objective determines the course design and teaching method. However, there is no consensus on what should be given priority in legal English classes, law or language. Supporters of the former argue that legal English teaching should familiarize students with the knowledge of the legal system and legal culture, raise their legal awareness 
and develop their professional skills through the English language [3]. Supporters of the latter hold that the major objective of legal English courses is to apply the theories of applied linguistics to explore the characteristics of legal documents [4].

The problem with these two seemingly efficient learning objectives is that both of them separate the mastery of content from the development of language skills. Both of them neglect the students' needs. Only after learners' need is identified, teaching objectives and teaching methods are able to be settled down. According to Du [5], the two highly demanding requirements of legal English course are the command of law knowledge and students' communication ability in legal English. However, the current practice of legal English courses fails to meet these demands in that it mostly imparts both linguistic and law knowledge down a one-way road, i.e. from teacher to students. Little time is spent on interaction. No wonder students complain that they have learned nothing practical. To cope with the current problems in legal English teaching, it is urgent to find out a valid teaching method of practical significance.

\section{A Study of Integrating Nunan's Six Elements of Task into Legal English Class}

David Nunan [6] identifies six key elements of task as goals, input, activities, role of teacher, role of learner and setting. The relationship between these six elements is illustrated as follows:

\section{$\begin{array}{llll}\text { Goal } & \searrow \\ \text { Input } & \rightarrow \\ \text { Activities } & \nearrow\end{array}$ Tasks $\quad \leftarrow \begin{gathered}\text { Teacher role } \\ \text { learner role } \\ \text { settings }\end{gathered}$}

Figure 1. A framework for analyzing communicative tasks [6]

As the above framework suggests that the task is central to instruction. Nunan [6] defines it as a piece of meaning-focused work involving learners in comprehending, producing, and/or interacting in the target language, and that tasks are analyzed or categorized according to their goals, input data, activities, setting and roles. As noted by Prabhu [7], students may learn more effectively when their minds are focused on the tasks, rather than on the language they are using.

The following is a research that the author has done to college students in China University of Political Science and Law by integrating the six elements identified by Nunan in order to illustrate how each element is implemented and to study how these elements systematically exert their influence on each of the steps of legal English teaching so as to make it more interactive and contextualized.

The following is the outline of the six elements of a particular class on Miranda Warnings, which is to be explained in great detail. It is worth noting that each of the tasks designed for this class involves more than one of the six elements.

The goal of this particular class is two-fold, i.e. the mastery of the knowledge of law and the improvement of English communication of that knowledge. To be specific, the objective of this class is similar to that of the traditional one, i.e. to familiarize students with the origin of Miranda Warnings, its development, key cases and its use in different U.S. jurisdictions. But more than that, there is one added objective that plays a key role in the design of this class, that is, besides the simple impartation of the knowledge of language and law, real-life situation practice of such knowledge is offered to make up for one of the major criticisms of teaching English for specific or professional purposes, i.e. professional practice is left out, except for providing context of specific analysis [8].

The input includes teachers' instruction and the materials that the learners work on. In this case, the mastery of input knowledge is completed preferably through the reading task assigned to students which is supplemented by teacher's in-class instruction of key points, both linguistic and legal. By doing so, the input step guarantees the students' possession of basic knowledge of law, improves their English reading skills and largely saves in-class time, most of which is allotted to the follow-up activities. In this case, the input is assigned to students to learn as a pre-class task which comprises (1) Setting Goal: the mastery of both language and content used in the activities that follow. (2) Activity: students collecting basic information needed on Miranda Warnings. (3) Material: text and online materials; (4) Time: before class.

Specifically, students are asked to read the text materials before class on how and why there is such a thing as Miranda Warnings so that they get familiar with the key case of Miranda v. Arizona which has defined Miranda Warnings. Since what is provided in the textbook is only a brief introduction, students are divided into several groups to conduct a collaborative online searching for authentic input which will certainly narrow the gap between classroom and real world. That's when they find relevant information and more importantly, confront problems such as the use and translation of certain legal terms, for example, the difference of "condemn", "convict" and "sentence" as well as problems concerning the legal background and history of that case, for example, top priority of the police to get evidence vs. coerced confession. This problem-awareness process is meaningful in that it, on the one hand, triggers students' implicit learning and on the other hand, encourages in-class teacher-students instruction or discussion on "unpredicted" problems.

The activities are the center of task on the basis of the aforementioned goal and input. In this case, what actually happens in class is that instead of teacher's one-way instruction and students' repeated drills on the structure and vocabulary of legal English, students are offered real-life 
situations to practice what they actually do with the input.

In the while-task, students are asked to do two kinds of activities, i.e. structured activity and unstructured activity. The structured activity is composed of (1) Setting Goal: consolidation of the input; (2) Activity: retelling and recasts; (3) Material: input; (4) Time: one class period.

In detail, students have to contribute as much as they gain by retelling the input, i.e. the case of Miranda v. Arizona. Differing from retelling in traditional English class where students retell the whole story one after one simply for homework checking, this activity requires each student in the class to make one-sentence contribution to the retelling of the whole case based on the outline given by the teacher. The activity is "structured" in such a way that it is possible to predict the exact language that is needed in order to perform the activity. Therefore, students can consolidate the mastery of language in class by teacher's highlighting selective features of the input. The technique used in this highlighting process is recast, i.e. repetition of a learner's incorrect utterance, but with changes made in order to make it correct. Recasts are more effective than correct models in bringing about short-term improvement in learner language [9]. Provided good mastery of the input, this recast process can achieve better result if it is done by peers with the guidance of the teacher. Besides this explicit learning triggered by structured activity, it is more meaningful that after the correction of language forms achieved by recasts, students are equipped with the basic language to perform the unstructured activity that follows.

Unstructured activity is the synonym of authentic communication. In this sense, the unstructured activity revives more content than language. It consists of (1) Setting Goal: activating the input in a real-life situation; (2) Activity: role play; (3) Material: input and recasts; (4) Time: one class period. The activity in this stage centers on a case study. Authentic interest is one part of the principle of authenticity which is vital to task-based instruction [6]. According to Zhang [10], 80\% of the students think legal English courses are more attractive by adopting case studies which unfortunately are seldom used because of the limit of class hours and the large number of students. But as a matter of fact, this will not be a problem if reading and writing are done before and after class respectively and students are divided into groups responsible for a particular part of the activity.

The details of this case is that one group of the students role play each party in the case of Berghuis v. Thompkins which has refined Miranda, particularly reviving the interrogation on Thompkins while some others play either the judges of the state and federal court or the judges with dissenting opinions. All this is done based on an in-depth investigation of relevant information that students have collected and analyzed prior to class. This information processing procedure offers students a theoretical setting for a contextualized process of their role play in class and also helps develop their critical thinking. What is crucial in students' involvement in the real situation activities is that it gives students an opportunity to internalize the content knowledge they have learned about law to communicate in real life law-related activities. It is by this way that the input content knowledge and training of English skills are brought together so that students are provided with both linguistic and extra-linguistic skill building. But for such successful activities to take effect, the whole process is largely dependent on the change of the role of teachers and that of students.

Traditional legal English classrooms are more teacher-centered, which hinders students from more interpersonal communication. Students are passive recipients rather than active participants spending most of the class time busy with note-taking, while teachers are engaging in explaining and translating. How can such a teaching mode help to improve students' ability to deal with foreign cases and communicate smoothly with foreign counterparts based on their law knowledge and English competence? Since tasks gives priority to communication between students as conversational partners rather than the command of language forms, teachers are more like monitors who facilitate the smooth progress of activities and supporters who help students to mobilize the input in a task. Teacher "controls" the activity by creating a setting which he thinks is suitable for both structured and unstructured activity to carry out. But he has less control in the latter than in the former over the actual language those students will need. And this is why the teacher has to monitor for a smooth unstructured activity to be done according to what he wants the students to learn from each activity and his pre-class design of its procedure.

The setting is crucial for the tasks to carry on. Due to the large number of students in a legal English classroom, it is not easy to go on with any task. Therefore, the perfect setting that fits this particular task-based class is group work so that every student is involved in one part of each task.

Seen from this particular case, the integration of Nunan's six elements of task helps to improve students' competencies in legal English. Activities are designed by teachers to engage students in a practical and functional use of the input of both language and content in particular settings for the purpose of using what they have learned in real-life law-related situations. In this sense, it provides a purpose for classroom activities which go beyond the practice of language [11].

\section{Implications and Conclusions}

In tasks, teachers set language-learners genuinely purposeful, problem-oriented, or outcome-driven activities, which are thus comparable to real world ones, for the sake of encouraging meaningful communication and providing a context to study language [12]. However, for this teaching mode to be effective, a number of problems inherent in the 
exam-oriented education system should be dealt with because a mismatch between instructional methods and the learning approach is very likely to create an obstacle to learning [13]. Superficial learning is often a problem in language education [14], for example when students, instead of acquiring a sense of when and how to use which linguistic or legal knowledge, memorize all that they need for the exam next week and then promptly forget it. Therefore, apart from a change in the students' concept about what learning is, an extra step is needed to give students an opportunity to reflect on what they have got from their involvement in the tasks. According to Nunan [15], a task usually requires the teaching to specify what will be regarded as successful completion of the task. In the case of this teaching mode, one final step of the successful completion of the task, i.e. post-task is that students are better inspired by writing an after-class report of the analysis of the activities having been dealt with in class. It, on the one hand, transfers both the content and language that the students have learned into English writing which is also a part of legal English learning. On the other hand, it raises the students' awareness of what they need to improve.

Feng [16] describes legal English as the customary and professional language used by drafters, legislators, lawyers, judges, litigants, law enforcement officials, and other law researchers in the common law jurisdiction. This definition indicates that the teaching of legal English, in essence, should be functional. Instead of focusing on the distinctive features of legal English at the level of lexicon, syntax, rhetoric, discourse structure and so on, students are encouraged to involve themselves in dealing with specially designed law-related activities by incorporating the six key elements of task identified by Nunan so that they are able to develop their language use, improve their communicative competence and consolidate their content mastery.

\section{REFERENCES}

[1] Qiao L. Analysis on the teaching experience of legal English instruction under the guidance of two high requirements. Journal of Ningxia University. 2012; 34 (5): 188-192.

[2] Liu G L. The application of constructivism to legal English teaching. Education for Chinese After-school. 2009; 5: 78-79.
[3] Guo Q. On the rationale of legal English curriculum Design. Journal of Shandong Foreign Language Teaching. 2004; 1:69-70.

[4] Man Y. Legal English teaching and training of international law talents. Journal of Beijing International Studies University. 2004; 2: 31-36.

[5] Du JB. The attainment of two high requirements of legal English curriculum. Journal of Guangdong University of Foreign Languages. 2006; 2: 76-80.

[6] Nunan D. Designing tasks for the communicative classroom. London: Cambridge University Press; 1989.

[7] Prabhu NS. Second language pedagogy. New York, Toronto: Oxford University Press; 1987.

[8] Bhatia VK. Genre analysis, ESP and professional practice. English for Specific Purposes. 2008; 27:161-174.

[9] Lyster R. Negotiation of form, recasts and explicit correction in relation to error types and learner repair in immersion classrooms. Language Learning. 1998; 48(2): 183-218.

[10] Zhang YY. Redesigning the teaching objective and method of college legal English. Higher Education Forum. 2004; 5: 111-112.

[11] Crystal D. A dictionary of linguistics and phonetics. Oxford: Blackwell; 1991.

[12] Plews JL, Zhao KX. Tinkering with tasks knows no bounds: ESL teachers' adaptations of task-based language teaching. TESL Canada Journal. 2010; 28(1): 41-59.

[13] Mirghani HM, Ezimokhai M, Shaban S, Berkel HJ. Superficial and deep learning approaches among medical students in an interdisciplinary integrated curriculum. Education for Health. 2014; 27(1):10-14.

[14] Larsson J. Problem-based learning: a possible approach to language education? [Internet]. [Place unknown]: Polonia Institute, Jagiellonian University; 2001. [cited 2013 January 27]. Available from http://en.wikipedia.org/wiki/Task-based language_learning.

[15] Nunan D. Communicative tasks and the language curriculum. TESOL Quarterly. 1991; 25(2):279-295.

[16] Feng GL, A study on legal English teaching of law majors. Forward Position. 2013; 3: 94-95. 